\title{
A longitudinal study of environmental salmonella contamination in caged and free-range layer flocks
}

Andrew Wales, Mark Breslin, Ben Carter, Robin Sayers, Robert Davies*

Department of Food and Environmental Safety, Veterinary Laboratories

Agency, Woodham Lane, New Haw, Addlestone, Surrey KT15 3NB, United Kingdom

Author for correspondence: Robert Davies

Telephone: 01932357361

Fax: $\quad 01932357595$

E-mail: r.h.davies@vla.defra.gsi.gov.uk

Running title : Salmonella in layer flocks 


\begin{abstract}
The environmental contamination by salmonella was examined over a 12-month period in 74 commercial layer flocks from eight farms in the UK, which previously had been identified as being contaminated with salmonella. Samples of faeces, dust, litter, egg belt spillage and wildlife vectors were taken, plus swabs of cages, feeders, drinkers, floors, egg belts and boots. Some sampling was performed in each month of the year. Numerous serovars were detected but Salmonella Enteritidis was the only persistent serotype found among single-age flocks. There was a significant correlation between qualitative environmental samples and semiquantitative faeces samples. The level of environmental contamination increased significantly over time. There were significant temperature and seasonal effects upon contamination. Wildlife vectors proved to be sensitive samples for the detection of salmonella. The efficacy of cleaning and disinfection upon residual salmonella contamination, and upon subsequent flock contamination, was highly variable between and within premises.

The variability between detected prevalences over time and between flocks indicates a need for regular, sensitive monitoring of flocks for salmonella to permit targeting of control measures aimed at eliminating contamination of the layer environment by salmonella. There is substantial scope for improvement of cleaning and disinfection procedures.
\end{abstract}




\section{Introduction}

Salmonella enterica serotype Enteritidis is the most common identified cause of human salmonellosis in the UK (Health Protection Agency, 2005) and is amongst the most significant Salmonella serotypes in public health elsewhere, including other parts of Europe (Fisher, 2004b) and North America (CDC, 2004). Undercooked and raw eggs have been heavily implicated in human infection with $S$. Enteritidis (Coyle et al., 1988; St Louis et al., 1988; Hogue et al., 1997; Palmer et al., 2000; CDC, 2004; De Buck et al., 2004; Crespo et al., 2005). This serotype is able to cause long term colonisation of the chicken reproductive tract and become deposited within egg contents (Berchieri et al., 2001; Okamura et al., 2001; Amy et al., 2004; Guard-Bouldin et al., 2004), and in addition will cause external contamination of the shell (Messens et al., 2005).

Improved biosecurity and hygiene in the UK poultry industry plus vaccination of the majority of commercial laying birds and broiler breeders, introduced in the mid to late 1990s, has been followed by a large reduction in reported incidents of $S$. Enteritidis in poultry and in humans (Anonymous, 2005; Health Protection Agency, 2005). Similar improvements have also occurred in some other countries (Wegener et al., 2003; Marcus et al., 2004; Mumma et $a l ., 2004)$ but there is still a significant reservoir of infection in commercial laying flocks (Adak \& Gillespie, 2004; Crespo et al., 2005). On commercial laying farms, persistent environmental contamination is currently considered to be the predominant problem (van de Giessen et al., 1994; Davies \& Breslin, 2003b; Gradel et al., 2004). Vaccination and other interventions such as competitive exclusion products do not reliably eliminate infection (Davies \& Breslin, 2003a; Davies et al., 2003), and their effectiveness is reduced where there is a heavy environmental challenge (Nakamura et al., 1994; Davies \& Breslin, 2003a,b; Nakamura et al., 2004).

Sampling the hen house environment, when coupled with suitable cultural techniques, has proved to be a sensitive and cost-effective method of monitoring salmonella carriage and excretion by layer hens (Kradel \& Miller, 1991; Henzler et al., 1994), and there is good agreement between the level of environmental contamination and the level of internal egg contamination and associated human disease (Altekruse et al., 1993; Henzler et al., 1994; Schlosser et al., 1995; Henzler et al., 1998; Mallinson et al., 2000). The sensitivity of environmental sampling varies between sample types (Davies \& Wray, 1996), and in caged layers samples from egg belts, dust close to birds or cage stacks and naturally accumulated pooled chicken faeces on droppings belts or scrapers have proved especially useful (Davies \& Breslin, 2001).

The prevalence of eggs contaminated internally or externally by salmonella from infected flocks appears to vary substantially, between less than $0.03 \%$ and $1 \%$ overall, but with up to $35 \%$ of some batches positive (reviewed by Davies \& Breslin, 2004; De Buck et al., 2004). Although technical factors may account for some variation between studies, it is unclear to what extent factors such as the time since the introduction of salmonella into the flock, the stage of lay and stressors such as hot weather can affect the level of infection in the flock and the production of contaminated eggs. Longitudinal studies are an appropriate way to address these questions, but the requirements of resource and cooperation by producers over months or years tends to limit the number and scope of such investigations. Consequently, there are few reports that have examined the levels of salmonella in laying houses and hens in lay over an extended period of time (Davison et al., 1999; Davies \& Breslin, 2003b; Kinde et al., 2005). The present report describes a longitudinal study conducted on several layer premises over a 12-month period. 


\section{Materials and methods}

Sample collection. A number of caged and free-range layer flocks were identified as having $S$. Enteritidis, by reference to the Zoonoses Order Database, or by personal contact or sampling. Approaches were made to the owners of these flocks and, when permission for intensive sampling had been obtained, they were visited and environmental samples were taken on successive occasions at differing stages of lay and also following depopulation, cleaning and disinfection. Sampling was systematic and targeted at sites and types of material that were likely to reveal salmonella contamination if present, based upon previous experience. The number and types of samples taken on each occasion was, in addition, determined by several factors. These included: the need for reasonable coverage of hen houses of differing sizes, the amount of certain sample types (e.g. dust, egg belt spillage and faeces) present according to design and usage, and constraints on access to certain sample types imposed by the hen house construction. On some visits an increased number of samples was taken to better define the distribution of salmonella within the house.

Samples were taken directly into $225 \mathrm{ml}$ of buffered peptone water (BPW: Merck) using gauze surgical swabs (Kleenex Readiwipes: Robinson Healthcare). For qualitative detection of salmonella, samples consisted of approximately $25 \mathrm{~g}$ faecal material, spillage from egg belts and from floors under cages, litter from free-range houses, dust from within and around cages and nest boxes (10 to $15 \mathrm{~g}$ ), rodent faeces ( 1 to $2 \mathrm{~g}$ ) and flies from adhesive paper or contact insecticidal traps ( 1 to $2 \mathrm{~g}$ ). In addition, sterile swabs soaked in BPW were used to sample the surfaces $\left(0.5 \mathrm{~m}^{2}\right)$ of egg belts, feeder troughs, cleaned droppings boards, floors beneath cages and the boots of free-range unit workers, The interiors of empty cages and drinker spillage cups or troughs were also swabbed, using composite samples of eight cages per swab. For semi-quantitative culture, bulked samples of chicken (approximately $30 \mathrm{~g}$ ) and rodent (approximately 1 to $2 \mathrm{~g}$ ) faeces were collected into dry pots.

All solid samples were returned to the laboratory at ambient temperature on the day of collection and processed immediately. Swab samples taken into BPW were, in addition, stored and transported in a cold box at below $10^{\circ} \mathrm{C}$. Mouse and rat carcasses were collected as available and $3 \mathrm{~g}$ of the liver, spleen and intestines were removed aseptically for culture at the laboratory.

Culture technique. For standard (qualitative) isolation, samples in BPW were pre-enriched at $37^{\circ} \mathrm{C}$ for $18 \mathrm{~h}$ and then $0.1 \mathrm{ml}$ of the pre-enriched mixture was inoculated onto modified semi-solid Rappaport-Vassiliadis agar with $0.01 \%$ novobiocin (MSRV; Difco 218681) and incubated at $41.5^{\circ} \mathrm{C}$ for 16 to $24 \mathrm{~h}$. Where opaque growth was seen on MSRV, a $1 \mu 1$ loop from the edge of the opaque growth zone was inoculated onto Rambach agar (Merck 107500). Rambach and associated MSRV plates were incubated at $37^{\circ} \mathrm{C}$ and $41.5^{\circ} \mathrm{C}$ respectively for $24 \mathrm{~h}$. The plates were examined and any MSRV plates on which the growth had spread widely, but which were negative for salmonella on the Rambach plates, were subcultured again onto Rambach agar. Representative Salmonella isolates were confirmed by complete serotyping at the salmonella reference laboratory at VLA - Weybridge according to the Kaufmann-White Scheme (Popoff, 2001).

For semi-quantitative culture (Wales et al., 2006a), $90 \mathrm{ml}$ BPW was thoroughly mixed with each $10 \mathrm{~g}$ bulked chicken faeces sample, and similarly $80 \mathrm{ml}$ BPW was mixed with $20 \mathrm{~g}$ samples. Ten or $20 \mathrm{ml} \mathrm{BPW}$ was added to pools of mouse and rat droppings respectively. From each of these initial tenfold or fivefold dilutions of chicken or rodent faeces, a $10 \%$ volume aliquot was dispensed into a universal container, to serve as the first in a decimal dilution series which was continued by taking $1 \mathrm{ml}$ from the initial dilution, mixing it with $9 \mathrm{ml} \mathrm{BPW}$ and successively repeating this step five times, adding $1 \mathrm{ml}$ of each consequent dilution to $9 \mathrm{ml} \mathrm{BPW}$. A pre-enrichment incubation at $37^{\circ} \mathrm{C}$ for $18 \mathrm{~h}$ was performed on all 
preparations, comprising the primary 1:10 or 1:5 mixture of faeces in BPW (' 0 '), the $10 \%$ volume aliquot of the same (' 1 '), and the decimal dilutions ('2' to ' 7 '). After incubation, $0.1 \mathrm{ml}$ of each of preparations ' 0 ' and ' 1 ' was cultured on selective (MSRV) and indicator (Rambach) media as described above. Preparations ' 2 ' to ' 7 ' were refrigerated, and were then similarly cultured if either the ' 0 ' or ' 1 ' preparations yielded growth. A semi-quantitative result was derived using the highest numbered preparation of each sample that yielded salmonella to indicate the most probable range of salmonella colony-forming units (cfu) in the original sample. A semi-quantitative score was given to each bulked chicken faeces sample, depending on the highest dilution that yielded salmonella upon culture (Table 1).

\section{Statistical analyses}

Prevalence versus semi-quantitative data. For each sampling visit from which semiquantitative data was obtained, the overall house prevalence of positive samples, derived from the standard (qualitative) isolation procedure, was assigned to one of four bands: $<20 \%$, $20-40 \%, 40-60 \%$ and $>60 \%$. These were tabulated against the semi-quantitative score (zero to five) from faeces (caged) or litter (free-range) samples. The exact probability for a linear by linear association test was calculated by StatXact software (Cytel, Cambridge, MA, USA).

Effects of season, temperature, stage of lay and vector activity. A non-linear mixed effects method was implemented to model the binary outcome: positive or negative for salmonella for each qualitatively-cultured sample. The data used for fitting the model was from caged single aged flocks, excluding the A\&L farm that was visited only once. The model was fitted using a logit-link and the binomial distribution within Proc NLMIXED, in SAS (SAS Institute, Cary, NC, USA) (Gilmour et al., 1985; Lindstrom \& Bates, 1990; Pinheiro \& Bates, 1995). The random effects matrix was estimated by a non-adaptive Gaussian quadrature method, with 201 points used. The linear predictor was:

$$
\eta=\mu+\tau_{i}+\beta_{0} \cdot M I H+\beta_{1} \cdot \text { Temp }_{i}+Z
$$

Where $\mu$ is the intercept, $\tau_{i}$ is the farm $(i=1,2, \ldots 5), M I H$ is the age of the birds prior to entering the active experiment, and $T e m p_{i}$ is the average monthly temperature recorded at the weather station closest to each farm $i$, as supplied by the Meteorological Office (2006). The random effect matrix $\mathrm{Z}$ includes the flock effect, over time. The model fitting process tested terms for their strength of evidence in affecting the odds of infection, including fly and wildlife infestation from semi-quantitative estimates of severity in each house, and the season of sample taken. Seasons were defined as: March-May (spring), June-August (summer), September-November (autumn) and December-February (winter). Since the temperature effect was completely nested within the season effect, nested models were compared and the likelihood ratio test was used to show if there was any variation attributable to season in addition to that accounted for by temperature. For each effect found to be significant, confidence intervals were calculated for the odds ratio of a sample being salmonella-positive when one state was compared to another, e.g. a particular number of months in house compared to an additional increment of one month.

\section{Results}

Sampling was performed over a 12-month period from August 2004 to July 2005 and a total of 74 flocks (59 caged, 15 free-range) were sampled from eight farms. All flocks had been vaccinated against salmonella, the majority using a live $S$. Enteritidis vaccine with or without 
a live $S$. Typhimurium component. In the remaining flocks an inactivated $S$. Enteritidis plus $S$. Typhimurium (Salenvac T) or a live $S$. Gallinarum vaccine providing cross-protection against $S$. Enteritidis (Nobilis $S G 9 R$ ) had been used. In addition, an oral competitive exclusion treatment had been given to approximately half the flocks. All farms except two (Gra and Sut) operated an all-in-all-out policy for stocking hen houses, potentially allowing thorough cleaning and disinfection (C \& D) of accommodation between flocks. Between one and four visits were made per flock at intervals of two to six months (tables 2 and 3), with flock ages varying between less than one and 19 months in house. Overall, and excluding rodent and other vector samples, $19.4 \%$ (736/3793) of cage house and $10.2 \%$ (85/833) of free-range house samples yielded salmonella. However, there was wide variation in the prevalence of positive samples between flocks and between farms (tables 2 and 3).

Salmonella serovars and phage types. Where $S$. Enteritidis was present on a farm, often there were two or three (in one case four) phage types detected (Table 4), although sometimes these were closely related types, such as PT4 and PT7. The same $S$. Enteritidis phage types were usually present in more than one flock on any one farm, and were present in both caged and free-range flocks where both were present on a premises. Samples taken after C \& D, and samples from successive flocks in the same house (Table 4), showed that endemic

$S$. Enteritidis phage types frequently persisted after C \& D and were present in contamination sampled from a subsequent flock. Other serovars, by contrast, typically were restricted to an individual flock and appeared once in a series of sampling visits (Table 4).

Semi-quantitative versus qualitative samples. Semi-quantitative culture using $20 \mathrm{~g}$ faeces was adopted for later samples following evidence of a superior sensitivity compared with a $10 \mathrm{~g}$ sample. Semi-quantitative data is included in tables 1 and 2, and no distinction is made between scores from the two sample sizes, as they were of the same order of magnitude. For values of prevalence and quantitative score from the same flock visit, the exact probability for a linear by linear association test is $\mathrm{p}=0.0001$, indicating a highly significant association between results from the two culture techniques. The same data are plotted against each other in Figure 1, which shows an apparently higher sensitivity of the multiple qualitative samples compared with the single bulked faeces sample, manifested as many more non-zero prevalence values plotted against zero semi-quantitative scores than vice-versa. Nonetheless, there were many samples that were negative for both techniques: there are 13 superimposed data points at the origin in Figure 1.

Stage of lay. Figure 2 shows the prevalence of salmonella-positive samples against time spent in-house by all single-age layer flocks. There is a substantial range of prevalences observed, although the trend appears to be upwards over time for sequentially-sampled flocks. Figure 3 shows the changes in salmonella prevalence over time in caged flocks where there had been two or three visits to occupied houses, for two sample sources: faeces/droppings boards and dust. Although the overall trends are upwards, this is more pronounced for the dust than for the faeces and droppings boards samples.

In the fitted non-linear mixed effects model, the time in house was significant in respect of prevalence $(\mathrm{p}<0.0001)$ with an average increase in odds ratio of 1.20 $(95 \%$ CI: $1.13,1.26)$ for each additional month in house.

Effect of temperature and season. The wide range and variation in the data is illustrated in Figure 4 showing, month by month, the prevalence of salmonella-positive samples from each flock visit as a deviation above or below the year-round average prevalence for that particular farm. 
The fitted non-linear mixed effects model revealed a significant $(\mathrm{p}=0.0014)$ effect between the odds of a positive sample and average monthly temperature. The average increase in odds ratio for salmonella detection in a sample was 1.08 (95\% CI: $1.03,1.12)$ for each additional degree Celsius. Furthermore, after additionally fitting the season effect it was found that the summer months significantly increased the odds of a sample being positive, when compared to the winter months ( $\mathrm{p}=0.0486)$, with an associated odds ratio of $3.41(95 \%$ CI: 1.01, 11.55).

Wildlife vectors and free-range paddocks. Details of isolations from rodents (predominantly pooled mouse faeces, also rat faeces and one set of mouse viscera), flies, litter beetles and free-range paddocks are given in Table 4. In flocks where no salmonella was detected in samples from the house, any vector and paddock soil samples were also negative. The overall prevalence of salmonella-positive samples from wildlife vectors was 34/88 (38.6\%), more than double the prevalence of positive samples from houses, which was $821 / 4626$ (17.7\%). Eleven positive samples were cultured by the quantitative method, yielding a range and mean of quantitative scores of $2-7$ and 4.36 respectively. Where isolates from vectors were phage-typed, the results generally correlated with those for samples from the same flock. In the statistical model, there was not enough evidence from the semiquantitative wildlife data (not shown) to conclude that the severity of fly infestation caused a change in the odds of infection $(\mathrm{p}=0.22)$.

Cleaning and disinfection. On 17 occasions a hen house was sampled immediately after $\mathrm{C} \& \mathrm{D}$, and in 10 of these cases the house had in addition been sampled shortly before depopulation. Figure 5 illustrates the degree of salmonella contamination before and after $\mathrm{C} \& \mathrm{D}$ in these 17 flocks, showing that the prevalence of positive samples fell after C \& D in $9 / 10$ cases, with no detectable salmonella following $C \& D$ in three of the 17 houses. The extent of contamination, as measured by the prevalence of positive samples, following $\mathrm{C} \& \mathrm{D}$ did not correlate with that detected before C \& D. Two notable examples are flocks 53 and 55, both from the same farm, with similarly high pre-depopulation salmonella prevalences but widely-differing post-C \& D contamination. For all flocks except 13, 29 and 70, an aldehyde disinfectant was used, which should have been effective even in the presence of residual organic matter. The breakdown of the data on contaminated sites seen post-C \& D (Figure 5), illustrates that all areas of the hen houses were prone to residual contamination, including those sites (cages, drinkers and feeders) likely to pose an early challenge to a new flock.

Examination of the data from new flocks in cleaned houses (tables 2, 3 and 4, plus data not shown) reveals that in three cases (flocks 26, 27 and 28, all on the same farm), high salmonella prevalences (40 to 60\%) were found on first visits within five weeks of occupying houses that had had no detected contamination after C \& D. In the 14 other cases where the changeover of flocks was monitored, post-repopulation salmonella prevalences were $20 \%$ or lower, even in houses with detected residual contamination post-C \& D. 


\section{Discussion}

The present study examined the environmental contamination by salmonella in 74 flocks from eight farms over a 12-month period. Sampling was performed in every month of the year, although the data from any one farm tended to be clustered within a few months, and two farms (A\&L and Gra) were visited only once. Sampling and detection was predominantly qualitative, yielding a positive or negative result for each sample and an overall percentage of positive samples (prevalence) figure for each site or flock. An abbreviated most probable number technique was used to estimate the number of viable salmonella cfu in a single bulked faeces sample from many flock visits and in wildlife vector samples from a few. The detected prevalence of contamination at any particular visit varied widely, with many flocks (for example 30, 31, 32 and 65) having no detectable salmonella on any occasion and others (40 and 55) having a single-visit prevalence in excess of $80 \%$. Those flocks that were sampled more than once often showed substantial variations in prevalence from one visit to the next, as illustrated in Figure 2. In most of the flocks examined, additional private monitoring was being carried out by cloacal swabs and environmental stick swabs at end of lay, and in only one case was contamination identified by these latter tests.

Typing of Salmonella isolates showed that $S$. Enteritidis was the only persistent serotype on any farm with the exception, on evidence from the present and previous studies, of $S$. Livingstone and $S$. Infantis on farm Sut, where individual cage houses were operated on a multi-age continuously occupied regimen. Whilst the occurrence of hen house contamination by non- $S$. Enteritidis serovars appears typically to be transient, they are nonetheless found frequently and there is evidence that certain serovars (e.g. S. Infantis) will contaminate both shells and contents of eggs. Attention to biosecurity, particularly in respect of feed and wildlife, should help reduce the chances of flock, and therefore egg, contamination by these non-Enteritidis serovars.

Several different phage types of $S$. Enteritidis $(4,6,7,21 \mathrm{~b}, 35)$ were detected and each farm exhibited a particular, and persistent, combination of these. Whilst PT4, which has been strongly associated with infection of layers in the UK and Europe (Cogan \& Humphrey, 2003), was detected on six of the eight farms, it was present in combination with other persistent $S$. Enteritidis phage types on five of these. This is consistent with previous findings (Liebana et al., 2001), whereby a variety of often closely-related phage types were seen in samples from poultry farms in geographically varied UK locations. In addition, the present findings show that these phage-type mixes can persist for an extended period of time on a farm. Where caged and free-range units existed on the same premises, a very similar mix of $S$. Enteritidis phage types and/or other serotypes was found in both production systems (Table 4). Egg surveys in the last fifteen years have shown evidence of an increasing diversity of $S$. Enteritidis phage types isolated from eggs in the UK, with a waning dominance of PT4 (Food Standards Agency, 2004). A long-term decline in the incidence of PT4 has also been observed in isolates from humans in Europe (Fisher, 2004a; Health Protection Agency, 2005). The present findings indicate that a diversity of $S$. Enteritidis phage types is also present at the likely source of egg contamination.

Statistical investigations included a comparison of the qualitative and semiquantitative culture techniques, which showed significant correlation. The latter technique shows promise as a research tool for the highlighting of areas and of vectors where a high level of challenge may be encountered (Wales et al., 2006a, b). In addition, a non-linear mixed effects model was used to examine the effects of various factors on the prevalence of contamination, incorporating the random effect of flock. One limitation upon this statistical analysis is that, because many flocks were first sampled in the cooler months towards the end of the calendar year, the environmental temperature and the number of months in-house 
exhibited some confounding, i.e. the 'time in house' and the 'temperature' parameters both contributed to the same effect, and there is little that can be done to isolate the effects of each of the two variables on the response (Woodward, 1999). However, in most cases the overlap was not complete and it is considered that the confounding is not severe enough to negate the main statistical conclusions. The problem could have been ameliorated had a longer study period and random sampling start dates been possible. Nonetheless, confounding is difficult to avoid in epidemiological studies where (in contrast to prospective experimental studies) different variables frequently cannot be controlled separately. Temperature and season present another issue: as temperature is heavily dependent upon season in the UK their effects cannot be considered independently. The effect of temperature was nested within season and the impacts of temperature and of season were assessed sequentially in the model. Therefore, the significance and odds ratio of temperature was unadjusted for season, whereas the effect of season was already adjusted for (i.e. in addition to) that of temperature.

When stage of lay (or the duration of house occupation) is considered, the data shows that the longest continuously-occupied houses (multi-age flocks 39, 40, 41, 48, 49, 50) typically were heavily contaminated with salmonella. The findings amongst the single-age flocks are more variable but there is a significant trend of an increase in the prevalence of contamination of the environment with time. The pattern of contamination appears to fluctuate more for faeces samples than for dust. As faeces are periodically removed in most systems, this difference may reflect fluctuating excretion by the hens (measured in faeces) against a background of a progressive build-up of Salmonella organisms in the henhouse environment (seen in dust).

When considering the effects of season, it might be expected that higher environmental temperatures in summer would increase bird stress and bacterial multiplication rates, resulting in higher levels of henhouse salmonella contamination. The statistical modelling does indeed show significant positive effects of temperature and, additionally, of season upon the detected prevalence of contamination. This is in the context of wide variation in detected contamination rates all year round. The season effect in addition to temperature may be mediated by factors such as an increase in vector numbers and activity. A more pronounced seasonal pattern is seen amongst the free-range than the caged flocks in the present study (Figure 4), but there are too few of the former flocks to draw any firm conclusions about seasonal differences between the two production systems. However, it may be that the control of bird stress and house temperatures differs significantly between the two production systems.

It is noteworthy in this context that in another UK study a seasonal effect was not seen for egg contamination (Davies \& Breslin, 2004). In the British climate, well-designed and well-insulated hen houses should not subject the occupants to excessive temperature fluctuations at any time of year, so a seasonal effect upon salmonella in eggs may be more marked in accommodation which has serious deficiencies in ventilation and insulation.

There is good evidence for the importance of wildlife vectors, especially rodents and flies, in the introduction to hen houses of salmonella and its maintenance thereafter (Davies \& Breslin, 2001; Guard-Petter, 2001; Mian et al., 2002; Garber et al., 2003). Wildlife vectors may also spread infection between flocks, by virtue of their mobility. The observations that samples from vectors not only reflected the sero- and phage types of the corresponding flock (as noted previously by Davies \& Breslin, 2003b), but were negative when the flock samples were negative and were positive at a high frequency in positive flocks, indicates the value of such samples for monitoring flock infection. Furthermore, they highlight the importance of the control of vectors, as the quantitative culture of rodent faeces showed that they frequently excrete high concentrations of salmonella, and they have the potential to amplify residual environmental contamination as well as to contaminate feeding and drinker systems directly. 
A strong association has been found between the number of mice and the detection of salmonella in layer houses (Garber et al., 2003), but in the limited data of the present study the association between wildlife score and prevalence was not found to be significant.

The variation in effectiveness of $\mathrm{C} \& \mathrm{D}$ between houses, even when in most cases similar disinfection agents were being used, suggests that other factors, such as the physical removal of organic matter and the mode of application of disinfectants, are highly significant in the eventual reductions in contamination that may be achieved. Amongst the farms in the current study, disinfection was poorly applied, in that products were usually used at insufficient concentration and application rates. Also, key areas such as drinkers, dropping belts and boards (which normally form the ceilings of cages) were often poorly cleaned, usually by dry cleaning only, and inconsistently sprayed with disinfectant. The use of multiage houses that cannot be effectively cleaned and disinfected between flocks appears, on the present evidence (flocks 39, 40, 41, 48, 49 and 50; Table 2), to afford very poor control of salmonella contamination. It is interesting that, in some of the present cases, apparently good $\mathrm{C} \& \mathrm{D}$ was followed by high prevalences of contamination within a month or so of repopulation. It seems likely that there was significant but undetected residual contamination. The evident difficulties in eliminating salmonella from any part of empty hen houses, plus the tendency of wildlife vectors to re-introduce salmonella (Garber et al., 2003) implies that control measures such as vaccination and intestinal competitive exclusion will be important components of salmonella control for the foreseeable future, even with salmonella-free replacement stock. With free-range units there is an additional issue of the persistence of salmonella on paddocks even after the removal of detectable contamination in the house, as seen with flock 69 in the present study.

\section{Conclusions}

The present investigation has shown a high degree of variation in the prevalence of salmonella contamination of hen houses, both between flocks on the same premises and within the same flocks over time. This has implications for monitoring programmes, when false negatives may occur. $S$. Enteritidis was predominant as the persistent serotype, and differing combinations of $S$. Enteritidis phage types proved stably persistent on various farms. The study reconfirmed the value of sampling wildlife vectors and their faeces, if present. There was a significant tendency to increased contamination with increasing flock age, but the temporal patterns of salmonella contamination in the first months of lay can be highly variable. There may be significant differences between contamination patterns over time in faeces and non-faeces samples. There were significant effects of temperature and season upon salmonella contamination. In all cases there was a clear need to improve both rodent control and $\mathrm{C} \& \mathrm{D}$, and in order to make further progress the egg industry must acknowledge the additional cost in terms of baits, traps, house maintenance, disinfectants, additional downtime between flocks and the labour to achieve this when salmonella is present. It is also vitally important that sensitive monitoring is introduced for laying flocks so that additional controls can be introduced, since to routinely and repeatedly use such measures as are required to eliminate salmonella from infected premises would be prohibitively costly.

\section{Acknowledgements}

This work was funded by the Department for Environment, Food and Rural Affairs (Defra; Project OZ0321). The authors would like to thank farmers and their staff as well as Veterinary Laboratories Agency (VLA) laboratory staff for their invaluable assistance with this study. 


\section{References}

Adak, G.K. \& Gillespie, I.A. (2004) Salmonella epidemiology in the UK and Europe. Whither Salmonella. London: Royal College of Physicians.

Altekruse, S., Koehler, J., Hickman-Brenner, F., Tauxe, R.V. \& Ferris, K. (1993) A comparison of Salmonella enteritidis phage types from egg-associated outbreaks and implicated laying flocks. Epidemiology and Infection, 110, 17-22.

Amy, M., Velge, P., Senocq, D., Bottreau, E., Mompart, F. \& Virlogeux-Payant, I. (2004) Identification of a new Salmonella enterica serovar Enteritidis locus involved in cell invasion and in the colonisation of chicks. Research in Microbiology, 155, 543-552.

Anonymous (2005) Zoonoses report United Kingdom 2004. Department for Environment Food and Rural Affairs. London: DEFRA.

Berchieri, A., Wigley, P., Page, K., Murphy, C.K. \& Barrow, P.A. (2001) Further studies on vertical transmission and persistence of Salmonella enterica serovar Enteritidis phage type 4 in chickens. Avian Pathology, 30, 297-310.

CDC (2004) Salmonella Surveillance: Annual Summary, 2003. Centers for Disease Control and Prevention. Atlanta, Georgia: US Department of Health and Human Services.

Cogan, T.A. \& Humphrey, T.J. (2003) The rise and fall of Salmonella Enteritidis in the UK. Journal of Applied Microbiology, 94, 114-119.

Coyle, E.F., Palmer, S.R., Ribeiro, C.D., Jones, H.I., Howard, A.J., Ward, L. \& Rowe, B. (1988) Salmonella enteritidis phage type 4 infection: association with hen's eggs. Lancet, 2, 1295-1297.

Crespo, P.S., Hernández, G., Echeíta, A., Torres, A., Ordóñez, P. \& Aladueña, A. (2005) Surveillance of foodborne disease outbreaks associated with consumption of eggs and egg products: Spain, 2002 - 2003. Eurosurveillance Weekly, 10, issue 6. http://www.eurosurveillance.org/ew/2005/050616.asp Accessed 10th November 2006

Davies, R. \& Breslin, M. (2001) Environmental contamination and detection of Salmonella enterica serovar Enteritidis in laying flocks. Veterinary Record, 149, 699-704.

Davies, R. \& Breslin, M. (2003a) Effects of vaccination and other preventive methods for Salmonella Enteritidis on commercial laying chicken farms. Veterinary Record, 153, 673-677.

Davies, R. \& Breslin, M. (2003b) Observations on Salmonella contamination of commercial laying farms before and after cleaning and disinfection. Veterinary Record, 152, 283-287.

Davies, R. \& Breslin, M. (2004) Observations on Salmonella contamination of eggs from infected commercial laying flocks where vaccination for Salmonella enterica serovar Enteritidis had been used. Avian Pathology, 33, 135-146.

Davies, R., Liebana, E. \& Breslin, M. (2003) Investigation of the distribution and control of Salmonella enterica serovar Enteritidis PT6 in layer breeding and egg production. Avian Pathology, 32, 225-237.

Davies, R.H. \& Wray, C. (1996) Determination of an effective sampling regime to detect Salmonella enteritidis in the environment of poultry units. Veterinary Microbiology, 50, 117-127.

Davison, S., Benson, C.E., Henzler, D.J. \& Eckroade, R.J. (1999) Field observations with Salmonella enteritidis bacterins. Avian Diseases, 43, 664-669.

De Buck, J., Van Immerseel, F., Haesebrouck, F. \& Ducatelle, R. (2004) Colonization of the chicken reproductive tract and egg contamination by Salmonella. Journal of Applied Microbiology, 97, 233-245.

Fisher, I.S. (2004a) Dramatic shift in the epidemiology of Salmonella enterica serotype Enteritidis phage types in Western Europe, 1998-2003 - results from the Enter-net international Salmonella database. Eurosurveillance, 9, 43-45.

Fisher, I.S. (2004b) International trends in Salmonella serotypes 1998-2003 - a surveillance report from the Enter-net international surveillance network. Eurosurveillance, 9, 45-47.

Food Standards Agency (2004) Report of the survey of Salmonella contamination of UK produced shell eggs on retail sale. UK Food Standards Agency. http://www.food.gov.uk/science/surveillance/fsis2004branch/fsis5004eggs Accessed November $10^{\text {th }} 2006$. 
Garber, L., Smeltzer, M., Fedorka-Cray, P., Ladely, S. \& Ferris, K. (2003) Salmonella enterica Serotype enteritidis in table egg layer house environments and in mice in US layer houses and associated risk factors. Avian Diseases, 47, 134-142.

Gilmour, A.R., Anderson, R.D. \& Rae, A.L. (1985) The analysis of binomial data by generalized linear mixed model. Biometrika, 72, 593-599.

Gradel, K.O., Sayers, A.R. \& Davies, R.H. (2004) Surface disinfection tests with Salmonella and a putative indicator bacterium, mimicking worst-case scenarios in poultry houses. Poultry Science, 83, 1636-1643.

Guard-Bouldin, J., Gast, R.K., Humphrey, T.J., Henzler, D.J., Morales, C. \& Coles, K. (2004) Subpopulation characteristics of egg-contaminating Salmonella enterica serovar Enteritidis as defined by the lipopolysaccharide O chain. Applied and Environmental Microbiology, 70, 2756-2763.

Guard-Petter, J. (2001) The chicken, the egg and Salmonella enteritidis. Environmental Microbiology, 3, 421430.

Health Protection Agency (2005) Trends in selected gastrointestinal infections - 2004. The Communicable Disease Report Weekly, 15. http://www.hpa.org.uk/cdr/archives/archive.htm Accessed July 1st 2005.

Henzler, D.J., Ebel, E., Sanders, J., Kradel, D. \& Mason, J. (1994) Salmonella enteritidis in eggs from commercial chicken layer flocks implicated in human outbreaks. Avian Diseases, 38, 37-43.

Henzler, D.J., Kradel, D.C. \& Sischo, W.M. (1998) Management and environmental risk factors for Salmonella enteritidis contamination of eggs. American Journal of Veterinary Research, 59, 824-829.

Hogue, A., White, P., Guard-Petter, J., Schlosser, W., Gast, R., Ebel, E., Farrar, J., Gomez, T., Madden, J., Madison, M., McNamara, A.M., Morales, R., Parham, D., Sparling, P., Sutherlin, W. \& Swerdlow, D. (1997) Epidemiology and control of egg-associated Salmonella enteritidis in the United States of America. Revue Scientifique et Technique, 16, 542-553.

Kinde, H., Castellan, D.M., Kerr, D., Campbell, J., Breitmeyer, R. \& Ardans, A. (2005) Longitudinal monitoring of two commercial layer flocks and their environments for Salmonella enterica serovar enteritidis and other salmonellae. Avian Diseases, 49, 189-194.

Kradel, D.C. \& Miller, W.C. (1991) Salmonella enteritidis: observations on field related problems. Proceedings of the $40^{\text {th }}$ Western poultry diseases conference, Acapulco.

Liebana, E., Garcia-Migura, L., Breslin, M.F., Davies, R.H. \& Woodward, M.J. (2001) Diversity of strains of Salmonella enterica serotype Enteritidis from English poultry farms assessed by multiple genetic fingerprinting. Journal of Clinical Microbiology, 39, 154-161.

Lindstrom, M.J. \& Bates, D.M. (1990) Nonlinear mixed effects models for repeated measures data. Biometrics, $46,673-687$.

Mallinson, E.T., De Rezende, C.E., Tablante, N.L., Carr, L.E. \& Joseph, S.W. (2000) A management technique to identify prime locations of Salmonella contamination on broiler and layer farms. Journal of Applied Poultry Research, 9, 364-370.

Marcus, R., Rabatsky-Ehr, T., Mohle-Boetani, J.C., Farley, M., Medus, C., Shiferaw, B., Carter, M., Zansky, S., Kennedy, M., Van Gilder, T. \& Hadler, J.L. (2004) Dramatic decrease in the incidence of Salmonella serotype Enteritidis infections in 5 FoodNet sites: 1996-1999. Clinical Infectious Diseases, 38 Suppl 3, S135141.

Messens, W., Grijspeerdt, K. \& Herman, L. (2005) Eggshell penetration by Salmonella: a review. Worlds Poultry Science Journal, 61, 71-85.

Meterological Office (2006) Historic station data. Met Office, UK. http://www.meto.gov.uk/climate/uk/stationdata/index.html Accessed July 19th 2006.

Mian, L.S., Maag, H. \& Tacal, J.V. (2002) Isolation of Salmonella from muscoid flies at commercial animal establishments in San Bernardino County, California. Journal of Vector Ecology, 27, 82-85.

Mumma, G.A., Griffin, P.M., Meltzer, M.I., Braden, C.R. \& Tauxe, R.V. (2004) Egg quality assurance programs and egg-associated Salmonella enteritidis infections, United States. Emerging Infectious Diseases, 10, 17821789. 
Nakamura, M., Nagamine, N., Takahashi, T., Suzuki, S. \& Sato, S. (1994) Evaluation of the efficacy of a bacterin against Salmonella enteritidis Infection and the effect of stress after vaccination. Avian Diseases, 38, 717-724.

Nakamura, M., Nagata, T., Okamura, S., Takehara, K. \& Holt, P.S. (2004) The effect of killed Salmonella enteritidis vaccine prior to induced molting on the shedding of $S$. enteritidis in laying hens. Avian Diseases, 48, 183-188.

Okamura, M., Kamijima, Y., Miyamoto, T., Tani, H., Sasai, K. \& Baba, E. (2001) Differences among six Salmonella serovars in abilities to colonize reproductive organs and to contaminate eggs in laying hens. Avian Diseases, 45, 61-69.

Palmer, S., Parry, S., Perry, D., Smith, R., Evans, M., Nehaul, L., Roberts, R., Walapu, M. \& Wright, D. (2000) The role of outbreaks in developing food safety policy: population based surveillance of Salmonella outbreaks in Wales 1986-98. Epidemiology and Infection, 125, 467-472.

Pinheiro, J.C. \& Bates, D.M. (1995) Approximations to the log-likelihood function in the nonlinear mixedeffects model. Journal of Computational and Graphical Statistics, 4, 12-35.

Popoff, M.Y. (2001) Antigenic formulas of the Salmonella serovars. Paris: WHO Collaborating Centre for Reference and Research on Salmonella. Institut Pasteur.

Schlosser, W.B., Henzler, D.J., Mason, J., Hurd, S., Trock, S., Sischo, W., Kradel, D. \& Hague, A. (1995) Salmonella enteritidis pilot project report. U.S. Government Washington D.C.

St Louis, M.E., Morse, D.L., Potter, M.E., DeMelfi, T.M., Guzewich, J.J., Tauxe, R.V. \& Blake, P.A. (1988) The emergence of grade A eggs as a major source of Salmonella enteritidis infections. New implications for the control of salmonellosis. Journal of the American Medical Association, 259, 2103-2107.

van de Giessen, A.W., Ament, A.J. \& Notermans, S.H. (1994) Intervention strategies for Salmonella enteritidis in poultry flocks: a basic approach. International Journal of Food Microbiology, 21, 145-154.

Wales, A.D., Breslin, M. \& Davies, R. (2006a) Semiquantitative assessment of the distribution of Salmonella in the environment of caged layer flocks. Journal of Applied Microbiology, 101, 309-318.

Wales, A.D., Davies, R.H. \& Breslin, M. (2006b) Assessment of cleaning and disinfection in Salmonellacontaminated poultry houses using qualitative and semi-quantitative culture techniques. Veterinary Microbiology, 116, 283-293.

Wegener, H.C., Hald, T., Lo Fo Wong, D., Madsen, M., Korsgaard, H., Bager, F., Gerner-Smidt, P. \& Molbak, K. (2003) Salmonella control programs in Denmark. Emerging Infectious Diseases, 9, 774-780.

Woodward, M. (1999) Confounding and Interaction. In M. Woodward. (1999). Epidemiology: Study Design and Data Analysis 1st edn (pp. 145-190). Chapman \& Hall / CRC. 


\section{TABLES}

Table 1: Relationship between quantitative score and likely concentration of Salmonella organisms in a sample

\begin{tabular}{lcc}
\hline Score & \multicolumn{2}{c}{ Range of Salmonella colony-forming units } \\
\cline { 2 - 3 } & $10 \mathrm{~g}$ sample $\left(\mathrm{g}^{-1}\right)$ & $20 \mathrm{~g}$ sample $\left(\mathrm{g}^{-1}\right)$ \\
\hline 0 & Not detected & Not detected \\
1 & $0.1-1$ & $0.05-0.5$ \\
2 & $1-10$ & $0.5-5$ \\
3 & $10-100$ & $5-50$ \\
4 & $100-1000$ & $50-500$ \\
5 & $1000-10000$ & $500-5000$ \\
\hline
\end{tabular}


Table 2: Details of overall salmonella prevalence (positive samples/total samples) from caged layer flock houses, and of quantitative scores of salmonella concentration from bulked faeces samples

\begin{tabular}{|c|c|c|c|c|c|c|c|c|c|c|c|c|c|c|}
\hline Farm, visit & Flock n & nber, pos & e samples & otal samp & s taken; & mi quan & ive score $^{\mathrm{a}}$ & & & & & & & \\
\hline$\overline{A \& L}$ & $\overline{1}$ & 2 & & & & & & & & & & & & \\
\hline Nov & $0 / 25$ & $0 / 28$ & & & & & & & & & & & & \\
\hline C\&K & 3 & 4 & 5 & 6 & 7 & 51 & $51 \mathrm{PCD}^{\mathrm{c}}$ & & & & & & & \\
\hline Sept & $0 / 40 ; \underline{0}$ & $6 / 40 ; \underline{2}$ & $1 / 40 ; \underline{0}$ & & & $5 / 40 ; \underline{1}$ & $(9 / 60)$ & & & & & & & \\
\hline Nov & $1 / 40 ; \underline{0}$ & $12 / 40 ; \underline{1}$ & $0 / 40 ; \underline{0}$ & $0 / 40 ; \underline{0}$ & & & & & & & & & & \\
\hline Apr & $5 / 40 ; \underline{0}$ & $13 / 40 ; \underline{2}$ & & $0 / 40 ; \underline{0}$ & $3 / 40 ; \underline{0}$ & & & & & & & & & \\
\hline Coc & 8 & 9 & 10 & 11 & 12 & 13 & 14 & 15 & 16 & 17 & 18 & 70 & 73 & 74 \\
\hline Nov & $2 / 19 ; \underline{0}$ & $3 / 19 ; \underline{4}$ & $3 / 18 ; \underline{0}$ & $12 / 20 ; \underline{2}$ & $0 / 20 ; \underline{0}$ & $12 / 19 ; \underline{2}$ & $10 / 18 ; \underline{2}$ & $8 / 20 ; \underline{5}$ & $2 / 19 ; \underline{2}$ & & & $(16 / 57)$ & & \\
\hline $\mathrm{Feb}$ & $5 / 20 ; \underline{2}$ & $10 / 20 ; \underline{0}$ & $7 / 19 ; \underline{5}$ & $15 / 20 ; \underline{0}$ & $1 / 20 ; \underline{0}$ & $(9 / 63)$ & & & $4 / 19$ & $1 / 20 ; \underline{0}$ & $4 / 20$ & & & \\
\hline Apr & $9 / 20 ; \underline{2}$ & $7 / 20 ; \underline{0}$ & & $4 / 20 ; \underline{2}$ & $1 / 20 ; \underline{0}$ & & & & $2 / 20 ; \underline{3}$ & $0 / 20 ; \underline{3}$ & & & $1 / 20 ; \underline{0}$ & $1 / 20 ; \underline{0}$ \\
\hline Cots & 19 & 20 & 21 & 22 & 23 & 24 & 25 & 26 & 27 & 28 & 52 & 53 & 54 & 55 \\
\hline Aug & & & & & & & & & & & $22 / 40 ; \underline{0}$ & $28 / 40 ; \underline{5}$ & & \\
\hline Sept & & & & & & & & & & & $(4 / 60)$ & $(19 / 60)$ & $21 / 40$ & \\
\hline Oct & $1 / 40 ; \underline{0}$ & $2 / 40 ; \underline{0}$ & & & & & & & & & & & $(9 / 60)$ & \\
\hline Nov & & & $7 / 40 ; \underline{0}$ & $0 / 40 ; \underline{0}$ & $0 / 40 ; \underline{0}$ & $7 / 40 ; \underline{2}$ & & & & & & & & $32 / 40 ; 4$ \\
\hline Jan & $0 / 20 ; \underline{0}$ & $3 / 20 ; \underline{0}$ & & & & & & & & & & & & $1 / 60$ \\
\hline Mar & & & & & & $1 / 40 ; \underline{2}$ & $8 / 40 ; \underline{2}$ & & & & & & & \\
\hline May & & & $10 / 40$ & $10 / 40$ & $8 / 40$ & & & & & & & & & \\
\hline Jun & & & $(0 / 60)$ & $(0 / 60)$ & $(1 / 60)$ & & & & & & & & & \\
\hline Jul & $7 / 40 ; \underline{4}$ & $25 / 40 ; \underline{3}$ & & & & $29 / 40 ; \underline{4}$ & $4 / 40 ; \underline{2}$ & $16 / 40 ; \underline{0}$ & $21 / 40 ; \underline{1}$ & $24 / 40 ; \underline{2}$ & & & & \\
\hline Fld & 29 & 30 & 31 & 32 & 33 & 34 & 35 & 36 & 37 & 38 & 56 & & & \\
\hline Dec & $0 / 13$ & $0 / 13$ & $0 / 14$ & & & & & & & & $12 / 40 ; \underline{0}$ & & & \\
\hline Jan & $0 / 20$ & $0 / 20$ & $0 / 40$ & $0 / 20$ & $0 / 20$ & $0 / 20$ & $0 / 40$ & & & & $(5 / 60)$ & & & \\
\hline Jul & $7 / 20$ & & & & $1 / 20$ & $0 / 20$ & $1 / 20$ & $7 / 20$ & $1 / 20$ & $3 / 20$ & & & & \\
\hline Aug & $(10 / 60)$ & & & & & & & & & & & & & \\
\hline Gra & $39^{b}$ & $40^{b}$ & $41^{b}$ & & & & & & & & & & & \\
\hline Apr & $13 / 35 ; \underline{3}$ & $35 / 40 ; \underline{5}$ & $18 / 40 ; \underline{0}$ & & & & & & & & & & & \\
\hline Hum & 42 & 43 & 44 & 45 & 46 & 47 & & & & & & & & \\
\hline Oct & $0 / 40 ; \underline{0}$ & $6 / 40 ; \underline{1}$ & $0 / 40 ; \underline{0}$ & $1 / 40 ; \underline{0}$ & & & & & & & & & & \\
\hline Jan & $11 / 40 ; \underline{0}$ & $(2 / 59)$ & $0 / 40 ; \underline{0}$ & $4 / 40 ; \underline{0}$ & & & & & & & & & & \\
\hline Jun & (7/58) & & $0 / 40 ; \underline{0}$ & & $6 / 40 ; \underline{0}$ & $5 / 38 ; \underline{0}$ & & & & & & & & \\
\hline Sut & $48^{b}$ & $49^{b}$ & $50^{b}$ & & & & & & & & & & & \\
\hline Mar & $2 / 40$ & $45 / 60 ; \underline{3}$ & $29 / 60 ; \underline{0}$ & & & & & & & & & & & \\
\hline
\end{tabular}

Visits are listed in chronological order. ${ }^{\mathrm{a}}$ For key to numbers of salmonella per gram, see Table $1 .{ }^{\mathbf{b}}$ Multi-age flock. ${ }^{\mathrm{c}}$ Post cleaning and disinfection.

Results in parentheses are from samples taken immediately after cleaning and disinfection following removal of the indicated flock. 
Table 3: Details of overall salmonella prevalence (positive samples/total samples) from free-range layer flock houses, and of quantitative scores of salmonella concentration from bulked faeces samples

\begin{tabular}{|c|c|c|c|c|c|}
\hline \multirow{3}{*}{$\begin{array}{l}\text { Farm/visit } \\
\text { A\&L } \\
\text { Nov }\end{array}$} & \multicolumn{5}{|c|}{ Flock number, positive/total samples taken; semi quantitative score } \\
\hline & 57 & 58 & 59 & & \\
\hline & $0 / 40$ & $0 / 37$ & $0 / 37$ & & \\
\hline Fld & 60 & 61 & 62 & 63 & 71 \\
\hline Jan & $0 / 20$ & $0 / 18$ & $0 / 40$ & & $(5 / 50)$ \\
\hline Jul & & $25 / 39$ & $23 / 39$ & $8 / 40$ & \\
\hline Aug & & $(9 / 50)$ & & & \\
\hline Gra & 64 & & & & \\
\hline Apr & $3 / 8$ & & & & \\
\hline Hum & 65 & 66 & 67 & & \\
\hline Oct & $0 / 44$ & $0 / 50$ & & & \\
\hline Jan & $0 / 44$ & & $0 / 40$ & & \\
\hline Jun & $0 / 40$ & & $0 / 40 ; \underline{0}$ & & \\
\hline Sut & 68 & 69 & 72 & & \\
\hline Sept & $0 / 51$ & $7 / 41 ; \underline{0}$ & & & \\
\hline Oct & & $(0 / 25)$ & & & \\
\hline Mar & $1 / 40 ; \underline{0}$ & & $1 / 40 ; \underline{0}$ & & \\
\hline
\end{tabular}


Table 4: Details of Salmonella types isolated from layer houses and vectors

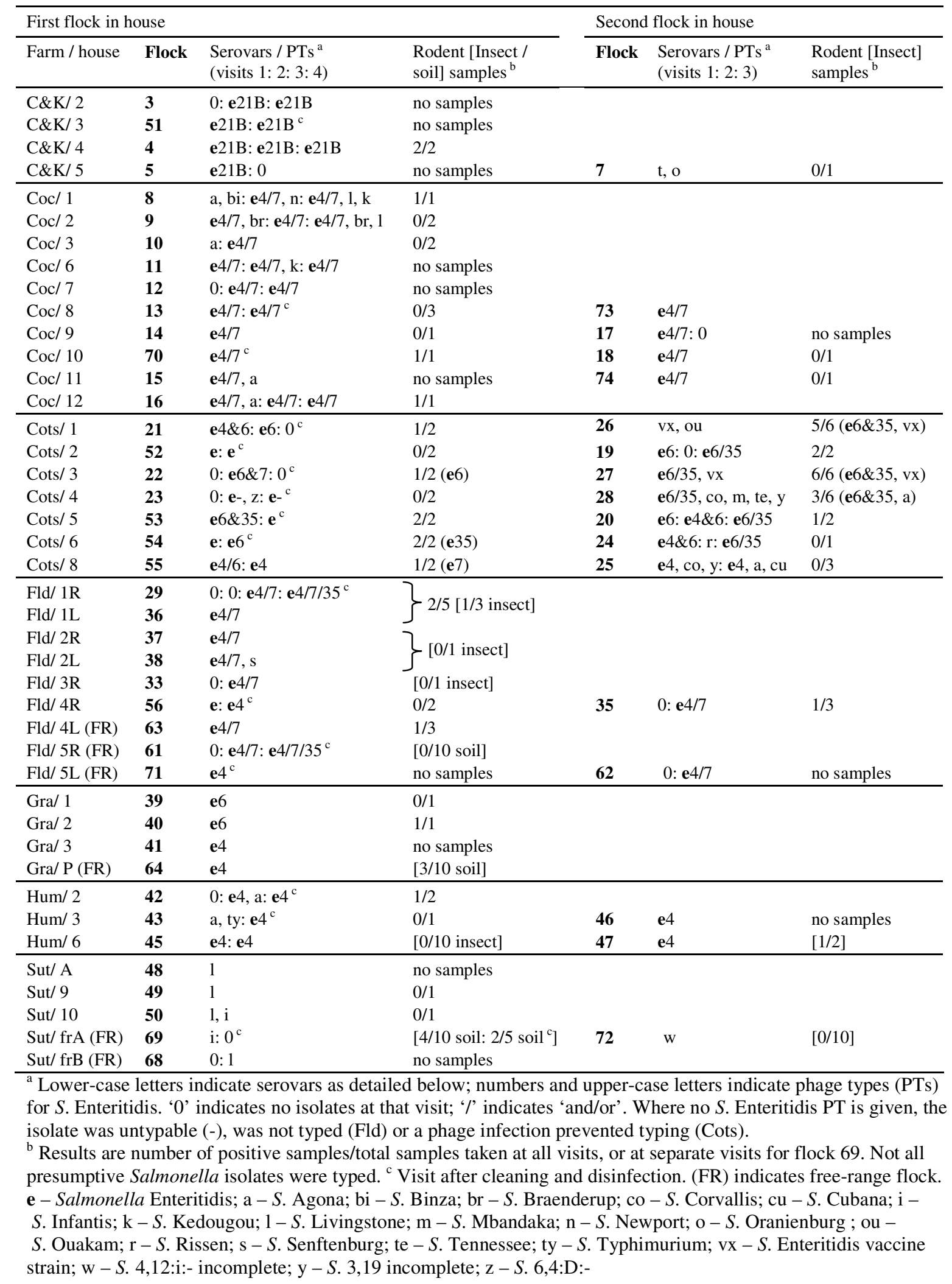




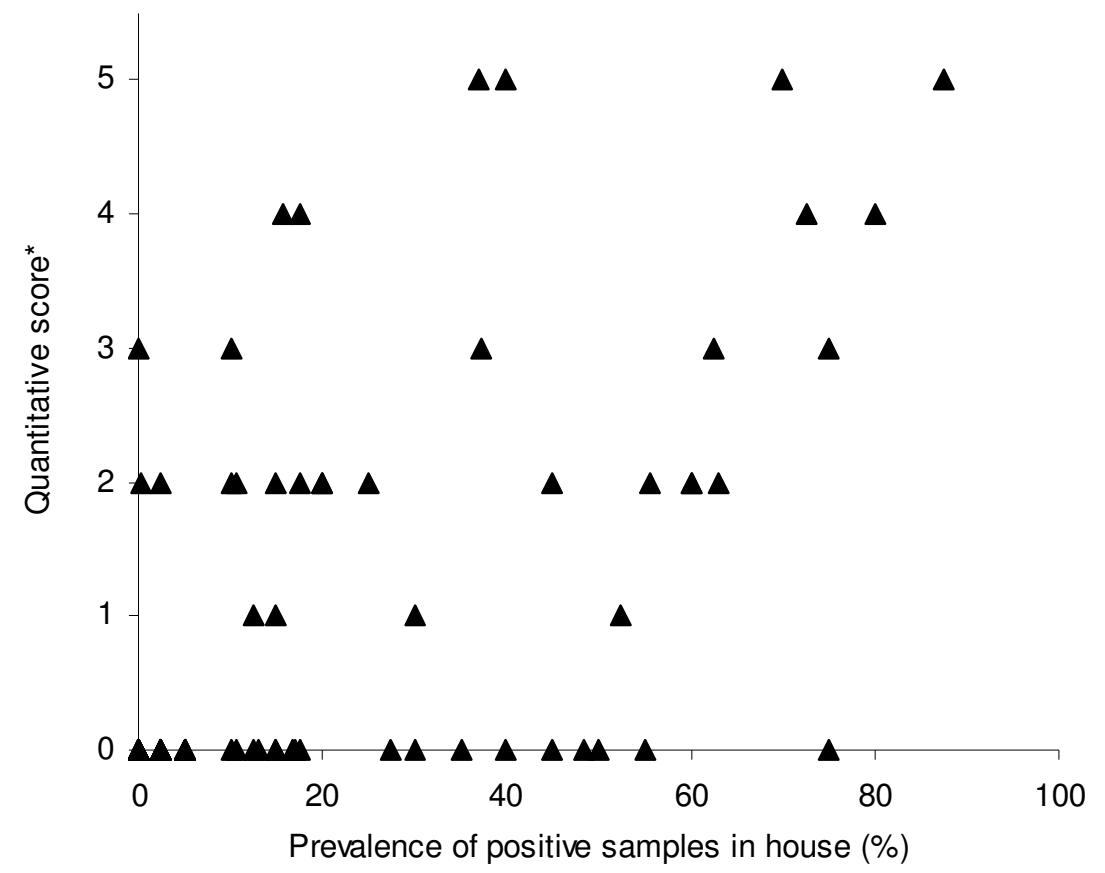

Figure 1: House salmonella prevalence versus quantitative culture of bulked faeces.

*Quantitative score is as detailed in Table 1 


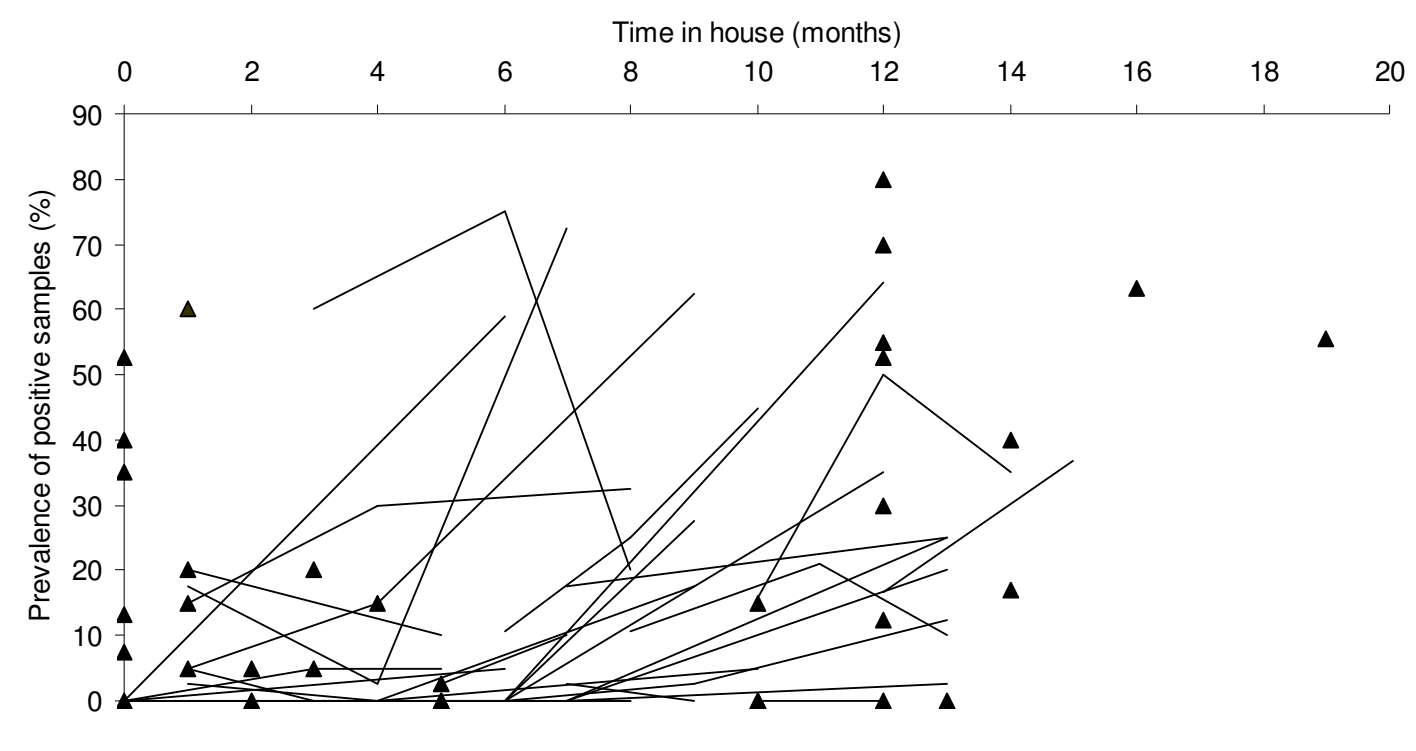

Figure 2: Overall prevalence of salmonella-positive samples over time in 66 single-age layer flocks. Prevalence values from consecutive visits to the same flock are joined by straight lines. Values from flocks sampled only once are indicated by triangles. 
a. Cage layers faeces / droppings board samples

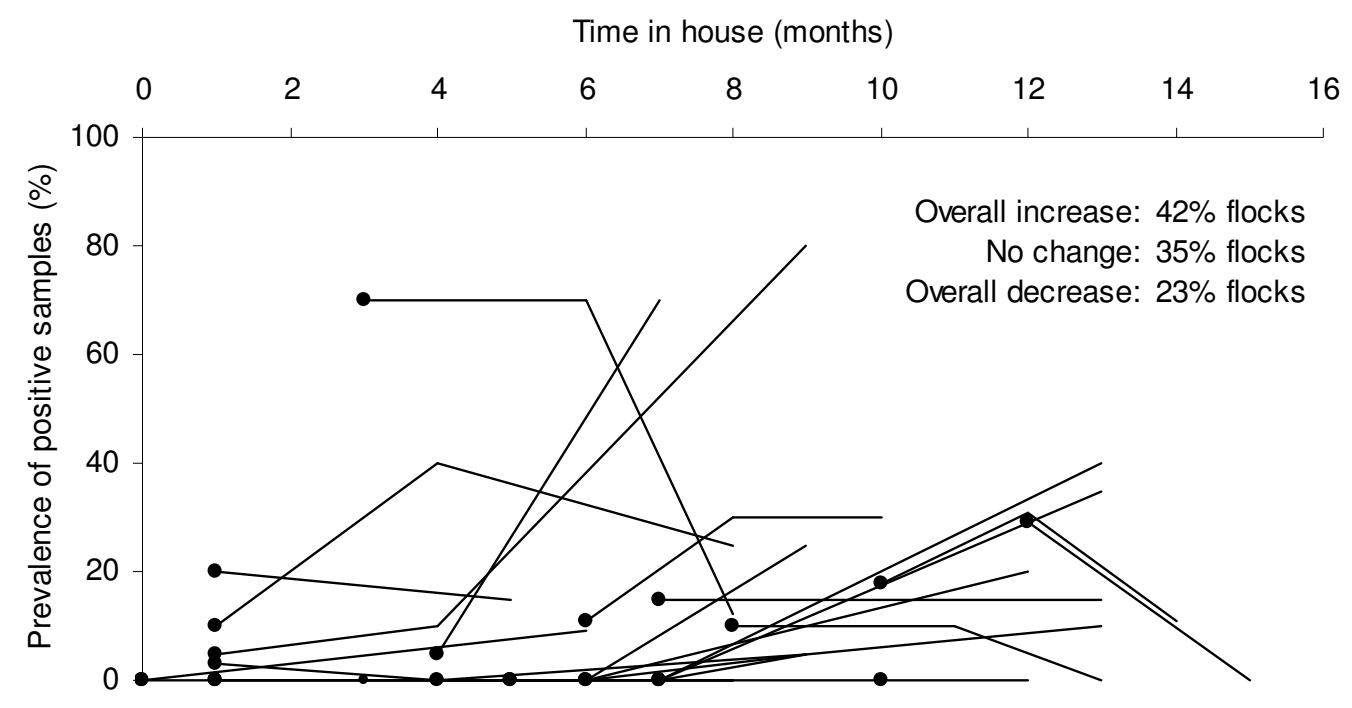

b. Cage layers dust and floor samples

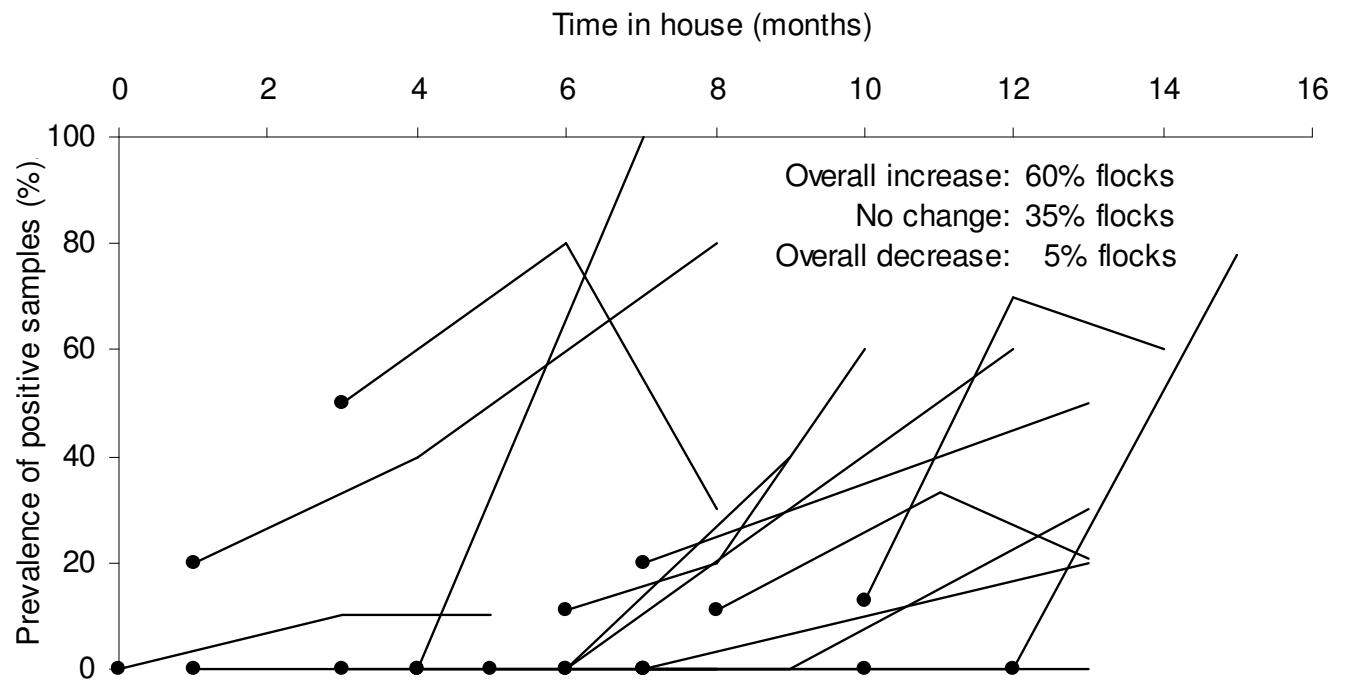

Figure 3: Changes in the prevalence of salmonella-positive samples over time. Prevalence values from initial visits are marked by solid circles and are connected to prevalence values from subsequent visits to the same flock by straight lines. 


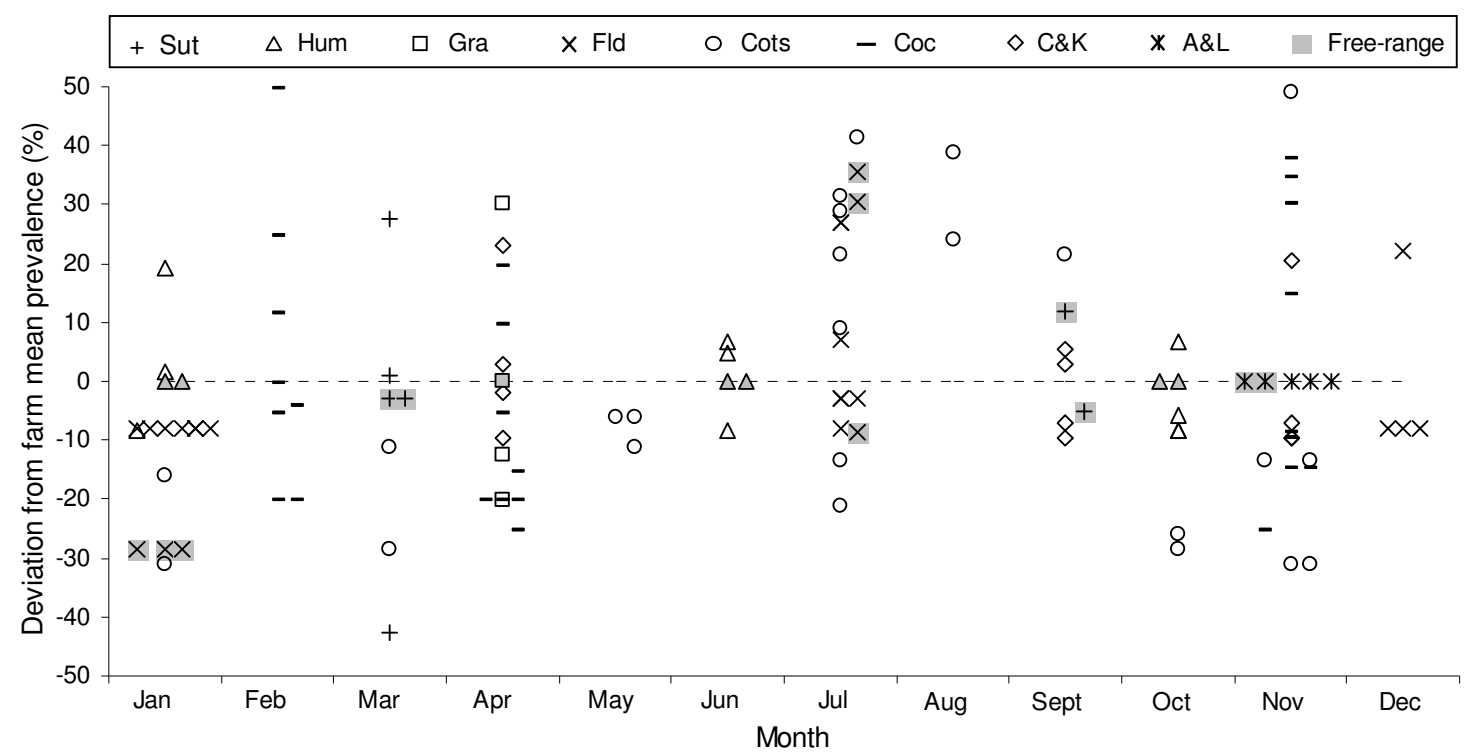

Figure 4: Month-by-month deviation from farm/housing system averages of salmonella prevalence for all flocks. 


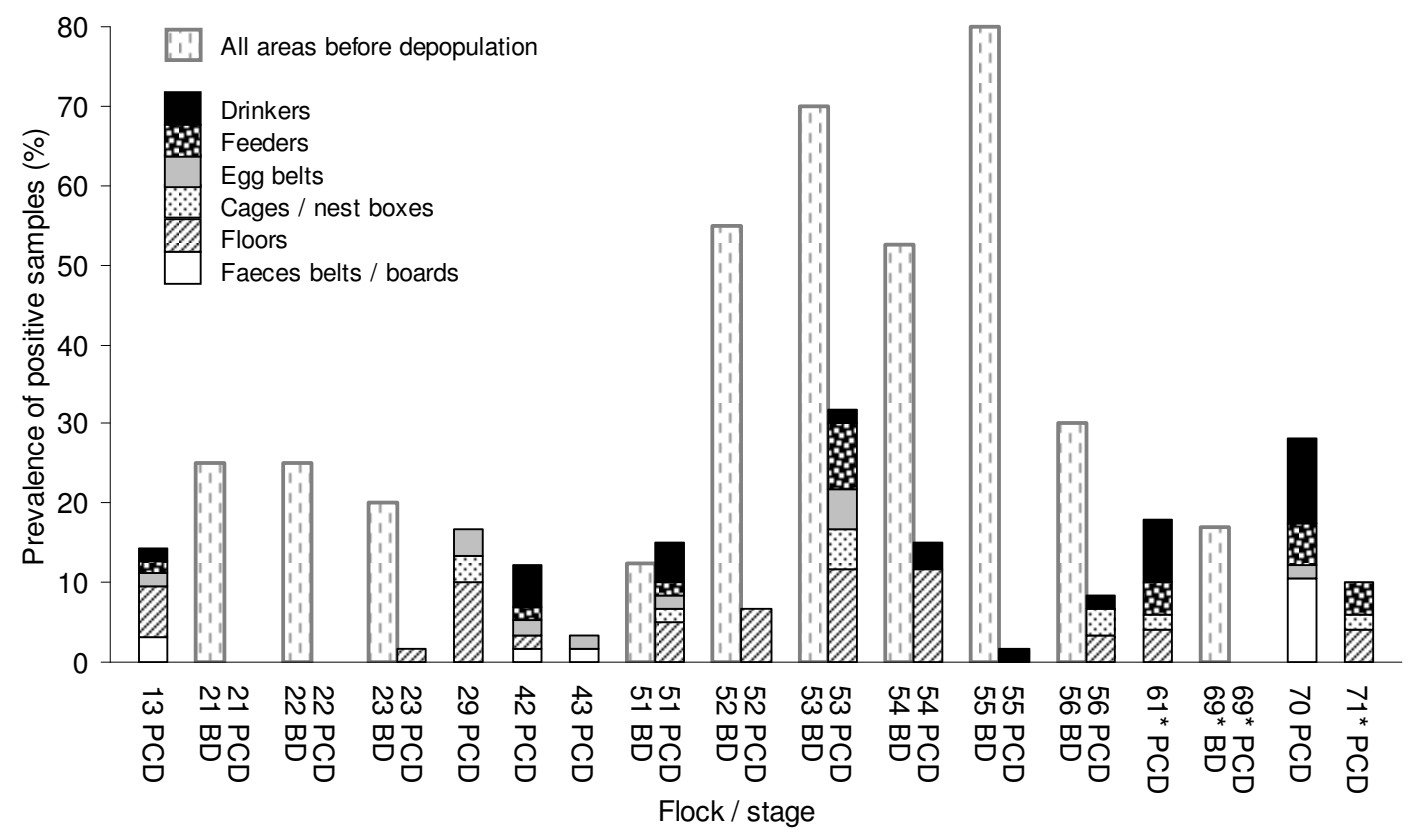

Figure 5: Results of cleaning and disinfection in 17 hen houses. *Free-range flock. 